Article

\title{
Lifestyle Patterns Are Associated with Elevated Blood Pressure among Qatari Women of Reproductive Age: A Cross-Sectional National Study
}

\author{
Mohammed Al Thani ${ }^{1}$, Al Anoud Al Thani ${ }^{2}$, Walaa Al-Chetachi ${ }^{2}$, Badria Al Malki ${ }^{2}$, \\ Shamseldin A. H. Khalifa ${ }^{2}$, Ahmad Haj Bakri ${ }^{2}$, Nahla Hwalla ${ }^{3}$, Lara Nasreddine ${ }^{3, \dagger, *}$ and \\ Farah Naja ${ }^{3, \dagger, *}$
}

${ }^{1}$ Public Health Department, Supreme Council of Health, Doha, Al Rumaila West, 42 Doha, Qatar; E-Mail: malthani@sch.gov.qa

${ }^{2}$ Health Promotion and Non Communicable Disease Prevention Division, Supreme Council of Health, Doha, Al Rumaila West, 42 Doha, Qatar; E-Mails: aalthani@sch.gov.qa (A.A.A.T.);

walchetachi@sch.gov.qa (W.A.-C.); balmalki@sch.gov.qa (B.A.M.); skhalifa1@sch.gov.qa (S.A.H.K.); abakri@sch.gov.qa (A.H.B.)

${ }^{3}$ Nutrition and Food Sciences Department, Faculty of Agriculture and Food Sciences, American University of Beirut, P. O. Box 11-0.236 Riad El Solh, 11072020 Beirut, Lebanon; E-Mail:nahla@aub.edu.lb

$\dagger$ These authors contributed equally to this manuscript.

* Authors to whom correspondence should be addressed; E-Mails: ln10@ aub.edu.lb (L.N.); fn14@aub.edu.lb (F.N.); Tel.: +961-1-350000 (ext. 4547) (L.N.); +961-1-350000 (ext. 4504) (F.N.); Fax: +961-1-744460 (L.N. \& F.N.)

Received: 12 June 2015 / Accepted: 27 August 2015 / Published: 9 September 2015

\begin{abstract}
Women of childbearing age are particularly vulnerable to the adverse effects of elevated blood pressure (BP), with dietary and lifestyle habits being increasingly recognized as important modifiable environmental risk factors for this condition. Using data from the National STEPwise survey conducted in Qatar in year 2012, we aimed to examine lifestyle patterns and their association with elevated BP among Qatari women of childbearing age (18-45 years). Socio-demographic, lifestyle, dietary, anthropometric and BP data were used $(n=747)$. Principal component factor analysis was applied to identify the patterns using the frequency of consumption of 13 foods/food groups, physical activity level, and smoking status. Multivariate logistic regression analyses were used to evaluate the association of the identified lifestyle patterns with elevated BP and to examine the socio-demographic
\end{abstract}


correlates of these patterns. Three lifestyle patterns were identified: a "healthy" pattern characterized by intake of fruits, natural juices, and vegetables; a "fast food \& smoking" pattern characterized by fast foods, sweetened beverages, and sweets, in addition to smoking; and a "traditional sedentary" pattern which consisted of refined grains, dairy products, and meat in addition to low physical activity. The fast food \& smoking and the traditional \& sedentary patterns were associated with an approximately 2-fold increase in the risk of elevated BP in the study population. The findings of this study highlight the synergistic effect that diet, smoking and physical inactivity may have on the risk of elevated BP among Qatari women.

Keywords: lifestyle pattern; elevated blood pressure; factor analysis; women; Qatar

\section{Introduction}

Globally, hypertension is the third leading cause of mortality and is a major risk factor for heart disease, stroke, and kidney failure [1,2]. According to the World Health Organization (WHO), 22.2\% of the adult population in 2014 had hypertension ( $24 \%$ of men and $20.5 \%$ of women) [3]. This prevalence was projected to increase to $29.2 \%$ (29\% of men and $29.5 \%$ of women) by year 2025 [4]. Among countries contributing significantly to this alarming increase in hypertension prevalence are countries of the Gulf Cooperation Council, where fast economic growth was accompanied by a steep rise in nutritional health problems and related disease. Qatar has recently emerged as the richest country in the world in terms of Gross Domestic Product (GDP) per capita. Though milestones have been accomplished in the betterment of life expectancy and health in the country, the WHO World Health Survey (WHS) in 2006 and later the WHO STEPwise survey in 2012 identified lifestyle-related non-communicable diseases, including obesity, diabetes and hypertension, as main health challenges, with hypertension rates increasing by $75 \%$ during this time interval $[5,6]$.

Of all adults, women of childbearing age are particularly vulnerable to the adverse effects of elevated blood pressure (BP) and hypertension. In addition to its effect on morbidity and mortality on the mother, hypertension in women of child-bearing age has been shown to be a major risk factor during pregnancy for both mother and child, possibly due to changes in blood flow to the uterus during pregnancy [7]. One in four women with pre-existing hypertension experience superimposed preeclampsia during pregnancy, placing the mother at high risk of organ damage and often necessitating early childbirth [8]. Furthermore, rates of preterm delivery, low birth weight, neonatal unit admission, and perinatal death are around three to four times higher among mothers with hypertension [7]. A recent systematic review and meta-analysis showed significant associations between maternal hypertension and congenital heart disease risk in the offspring (Relative Risk (RR) 1.8; 95\% Confidence Interval (CI) 1.5, 2.2) regardless of whether hypertension was treated or not [9]. These substantial short and long-term health risks of hypertension among women of child-bearing age make this age group an ideal target for the primary prevention of hypertension.

The escalating trend in hypertension prevalence coupled to significant downstream pathophysiological effects and enormous financial liabilities pose major public health concerns that necessitate the search for mitigating factors and strategies to address them. Prehypertension and elevated BP are recognized as frequent precursors of hypertension [10]. Dietary intake is an important modifiable environmental 
risk factor in the development and prevention of elevated BP and hypertension [11]. Studies on the association between dietary factors and BP have consistently shown that excess sodium and alcohol intake and inadequate intake of potassium increase BP [12]. However, the evidence for the association with other dietary factors has been less consistent. For instance, dietary protein appeared to reduce BP in a few randomized trials; however, such a relationship was not confirmed by long-term studies [13]. Furthermore, the optimal source of protein (e.g., plant or animal) implicated in BP reduction has not been also identified. It is also not clear whether the reduction of BP with a higher intake of protein is rather due to a concomitant reduction in carbohydrates [13]. Similarly, while high fiber intake has shown a modest reduction on BP [14], the benefits of dietary fiber are difficult to distinguish from the benefits of an increase in vitamins and minerals, such as potassium, coming from the same fibrous plant-based foods [12]. To overcome such inconsistencies, nutrition epidemiologists have proposed studying dietary patterns as an alternative approach to single nutrients in evaluating diet-disease relationships [15]. Several studies have investigated the association between dietary patterns and hypertension [12,16,17], consistently showing an increased risk for hypertension with higher adherence to a "Western" dietary pattern [17].

Though dietary intake is a main modulator of BP and risk of hypertension, other behavioral factors such as smoking and physical activity have also been implicated as risk factors of hypertension and are important to consider in addressing prevention. Studying a single behavioral risk factor overlooks the fact that people are exposed to a combination of risk factors which are frequently interactive and/or synergistic [18]. Recently, a few studies have addressed the association between lifestyle patterns and weight status among children [19]; dysglycemia [20] and non-communicable diseases [18]. Not only does this approach account for the collinearity or intercorrelations between risk factors, it allows for a better understanding of high-risk behaviours as they cluster in real-life and thus produces more culturally sensitive public health recommendation that can be easily interpreted and followed by the general population.

Using data from the National WHO STEPwise s survey conducted in Qatar in year 2012, this study aimed at identifying lifestyle patterns among women of reproductive age in Qatar and investigating the association of these patterns with elevated BP. A secondary objective was to examine the socio-demographic correlates of the identified lifestyle patterns. Findings of this study will pave the way for the development of culturally sensitive evidence-based interventions strategies aimed at preventing elevated BP among women of child-bearing age in Qatar.

\section{Methodology}

\subsection{Study Design}

The data presented in this paper is a secondary analysis of the National STEPwise Survey conducted in Qatar during year 2012. The survey was conducted on a nationally representative sample of Qatari adults aged between 18 and 64 years. The survey design, including sampling and data collection, was modelled based on the WHO STEPwise approach to non-communicable disease risk factor surveillance. The sample consisted of randomly selected households based on a multi-stage cluster sampling. Clusters were selected from the seven municipalities of Qatar (Doha, Al Rayyan, Al Warka, Umm Salal, Al Khor, Al Shamal, Al Daayeen). The clusters were defined as a group of contiguous blocks (between 60 and 70 blocks). Using probability proportional to size sampling, a systematic random sample of 95 clusters 
was selected [21]. Within each cluster, 30 households were randomly chosen. Adults of Qatari nationality between the age of 18 and 64 years were eligible to participate in the survey. In the household, in case more than one subject was eligible, using a personal digital assistant (PDA) to generate a random number, only one adult was randomly selected. Out of the 2850 households approached, 2496 participated in the study (response rate 88\%). The Qatar WHO STEPwise survey protocol was granted ethical approval from the Supreme Council of Health and the Ministry of Development Planning and Statistics, Doha, Qatar. A written consent form was obtained from all study participants who were assured that all information they provided was strictly confidential, their participation is voluntary, and they have the right to refuse the participation and withdraw from the interview at any stage. Further details about the design and protocol of the Qatar STEPwise survey are found at Haj Bakri \& Al-Thani (2013) [6]. The present paper focused on women of child bearing age. The selection criteria were (1) female sex; (2) age between 18 and 45; (3) healthy (no known diagnosis of hypertension, other chronic diseases, or conditions that may affect dietary intake); and (4) not pregnant. Out of 776 women who meet the inclusion criteria, 29 had missing or incomplete data for BP, dietary and/or lifestyle information and hence were excluded from the analysis.

\subsection{Data Collection}

The participants were visited at their household by interviewers who were trained on the methodology of the survey and protocols of data collection prior to the initiation of field work. During the interview, participants responded to the questions of the interviewers which were based on a standard multi-component questionnaire and they have also undergone physical examination. The questionnaire included information about socio-demographic (age, sex, education, marital status, job type, parental consanguinity, family history of diabetes and hypertension) and lifestyle characteristics (smoking, physical activity and dietary intake). Smoking questions addressed the smoking status of the participants as well as his/her exposure to passive smoking (days/week). As recommended by the WHO STEPwise approach, the Arabic Global Physical Activity Questionnaire (GPAQ) was used to assess physical activity. The GPAQ covers several components of physical activity, such as intensity, duration, and frequency, and it assesses three domains in which physical activity is performed (occupational physical activity, transport-related physical activity, and physical activity during discretionary or leisure time) [22]. Total physical activity was calculated by weighting each type of activity by its energy requirements defined in MET (Metabolic Equivalent of Task)-minutes. The total MET-min were computed as the sum of all MET-min/week from moderate-to-vigorous-intensity physical activities performed for each of the three domains, and was later converted to total Met-min per day [23]. Three categories of physical activity (low, moderate, high) were assigned based on METS-min per week [24]. Dietary intake was assessed using a non-quantitative (without reference to portion size) food frequency questionnaire. A total of 13 food groups were included: refined grains, fruits, vegetables, milk and dairy products, meat, poultry, fish and sea food, beans, sweets, sweetened beverages, whole grains, and natural juices. Frequency of consumption was recorded as number of days per week the food/food group was consumed. No questions on alcohol were included for cultural and religious considerations. Besides providing information on usual intakes of a particular food or food groups of interest, such non-quantitative Food Frequecy Questionnaires (FFQs) have been particularly useful in identifying dietary patterns at the population 
level [25]. All components of the questionnaire were tested for cultural sensitivity on a sample of Qatari adults prior to the initiation of field work.

During physical examination, the BP, weight, height and waist circumference of participants were determined. BP, both systolic and diastolic, was measured through a calibrated Omron M7 sphygmomanometer (Omron BP785; China). Three readings were obtained for both systolic and diastolic BP at 5 minutes intervals. The average of the second and the third readings were used. Elevated $\mathrm{BP}$ was defined as either systolic pressure $\geqslant 130$ or diastolic pressure $\geqslant 85 \mathrm{~mm} \mathrm{Hg}[26,27]$.

Weight and height measurements were taken using standardized techniques and calibrated equipment. Subjects were weighed to the nearest $0.1 \mathrm{~kg}$ in light indoor clothing and with bare feet or stockings. Using a stadiometer, height was measured without shoes and recorded to the nearest $0.5 \mathrm{~cm}$. Body mass index (BMI) was calculated as the ratio of weight (kilograms) to the square of height (meters).

\subsection{Lifestyle Patterns Derivation}

Using the exploratory Principal Component Factor Analysis (PCFA), lifestyle patterns were identified based on the frequency of consumption of the 13 foods/food groups, physical activity (in Mets-Minutes), and smoking status (non-smoker, past smoker and current smoker). Prior to running the PCFA, the correlation matrix between all the variables was visually and statistically examined to justify undertaking the analysis. The chi square for Bartlett test of sphericity was significant at a $p$-value less than 0.05 , and the Kaiser-Meyer-Olkin test (KMO) was greater than 0.6, indicating that the correlation among the variables was sufficiently strong for a factor analysis. The number of factors retained was based on three criteria: (1) the Kaiser criterion (eigenvalues > 1); (2) inflection point of the scree plot (3) and the interpretability of factors. The factors were rotated by a Varimax rotation (orthogonal transformation). Factor loadings indicated the strength and direction of the association between the patterns and the lifestyle variables. Factor scores were calculated by multiple regression approach with each participant possessing a score on each of the three factors. These scores indicated the degree to which each subject's diet adheres to the identified pattern. For each pattern, participants were grouped into tertiles of pattern scores.

\subsection{Statistical Analyses}

In order to correct for the selection probabilities, the sample distribution was calibrated to the Qatari population totals using geographical and 5 year-age distributions. Data analysis was weighted using sampling weights calculated as the inverse of the sampling fractions. In weighting, the distribution of the 2010 Qatari population by municipality and 5 year age group was used as the reference [21]. Socio-demographic, lifestyle characteristics, eating habits and anthropometric measurements were described using means \pm standard deviations (SD) and proportions for continuous and categorical variables, respectively. The chi-square test, $t$-test and ANOVA were used to chart comparisons between groups. Multiple logistic regression analyses were applied to identify the socio-demographic and lifestyle correlates of adherence to the identified patterns. Adherence was defined as belonging to the third tertile of the pattern score. The associations of the lifestyle patterns with elevated BP were evaluated by means of multivariate logistic regression models, with tertiles of dietary patterns' scores as independent variables and elevated BP as the outcome variables. Belonging to the third tertile of a certain pattern's score indicated that the participants had higher adherence to this pattern when compared 
to other participants who belonged to the first and second tertiles. The multivariate logistic regression models were adjusted for variables found to be associated with either BP or the lifestyle patterns and these included age, education, marital status, parental consanguinity, family history BP, number of meals not eaten at home, exposure to passive smoking and BMI. The Statistical Package for the Social Sciences (SPSS, version 14.1, Chicago, IL, USA) was used for all computations [28] and a $p$-value $<0.05$ was considered significant.

\section{Results}

Socio-demographics, lifestyle and anthropometric characteristics of study participants by BP status are presented in Table 1. Out of the 747 women study participants, 105 (14\%) had an elevated BP. Study participants' mean age was $31.0 \pm 7.0$ years. Eighty $\%$ of subjects had high school or higher education level with almost 52\% working (either government $(47.7 \%)$ or private (4\%) employment), $29.6 \%$ were housewives. A considerable proportion (35.1\%) reported parental consanguinity. Family history of diabetes and hypertension were reported among $68 \%$ and $64.3 \%$ of participants, respectively. The majority of subjects were non-smokers $(97.7 \%)$ with only $1.5 \%$ being current smokers. Over $50 \%$ of subjects belonged to the low physical activity category, with walking constituting $55.5 \%$ of total physical activity. This percentage was higher than work (26.2\%) and leisure time (18.3\%) related activities. Thirty eight percent of subjects were obese $\left(B M I \geqslant 30 \mathrm{~kg} / \mathrm{m}^{2}\right)$. Comparisons between subjects with elevated versus those with normal BP showed that subjects with elevated BP were older (33.5 \pm 6.9 vs. $30.5 \pm 6.9$, $p<0.01)$, more likely to be married $(73.6 \% v s$. $63.7 \%$; $p<0.05)$; and have a family history of BP (77.4\% vs. 62.1\%; $p<0.05)$. Furthermore, obesity was more prevalent among subjects with elevated BP compared to those with normal BP $(50.0 \%$ vs. $35.2 \%, p<0.05)$.

Table 1. Weighted socio-demographics, lifestyle and anthropometric characteristics of study participants by blood pressure status ${ }^{\text {a }}(n=747)$.

\begin{tabular}{|c|c|c|c|c|}
\hline Variable Name & $\begin{array}{c}\text { Total } \\
n=747\end{array}$ & $\begin{array}{c}\text { Normal Blood } \\
\text { Pressure } n=642\end{array}$ & $\begin{array}{l}\text { Elevated Blood }{ }^{\dagger} \\
\text { Pressure } n=105\end{array}$ & Significance $^{\dagger \dagger}$ \\
\hline Age (years) & $31.0 \pm 7.0$ & $30.5 \pm 6.9$ & $33.5 \pm 6.9$ & $p=0.000 * *$ \\
\hline \multicolumn{5}{|l|}{ Education } \\
\hline Up to intermediate level ${ }^{b}$ & $140(20)$ & $113(17.6)$ & $24(22.9)$ & \multirow{3}{*}{$p=0.36$} \\
\hline Finished high school & $280(40)$ & $248(38.7)$ & $35(33.3)$ & \\
\hline University/graduate level & $326(43.7)$ & $280(43.7)$ & $46(43.8)$ & \\
\hline \multicolumn{5}{|l|}{ Marital Status } \\
\hline Not married & $261(34.9)$ & $233(36.3)$ & $28(26.4)$ & \multirow{2}{*}{$p=0.05 *$} \\
\hline Married & $486(65.1)$ & $409(63.7)$ & $78(73.6)$ & \\
\hline \multicolumn{5}{|l|}{ Job type } \\
\hline Governmental employee & $356(47.7)$ & $309(48.1)$ & $47(44.8)$ & \multirow{4}{*}{$p=0.42$} \\
\hline Non-governmental employee ${ }^{c}$ & $30(4.0)$ & $26(4.0)$ & $4(3.8)$ & \\
\hline Not working & $140(18.7)$ & $124(19.3)$ & $16(15.2)$ & \\
\hline Housewife & $221(29.6)$ & $183(28.5)$ & $38(36.2)$ & \\
\hline \multicolumn{5}{|l|}{ Parental Consanguinity } \\
\hline No & 485 (64.9) & $417(65.0)$ & $68(64.8)$ & \multirow{2}{*}{$p=0.97$} \\
\hline Yes & $262(35.1)$ & $225(35.0)$ & $37(35.2)$ & \\
\hline
\end{tabular}


Table 1. Cont.

\begin{tabular}{|c|c|c|c|c|}
\hline Variable Name & $\begin{array}{c}\text { Total } \\
n=747\end{array}$ & $\begin{array}{c}\text { Normal Blood } \\
\text { Pressure } n=642\end{array}$ & $\begin{array}{l}\text { Elevated Blood }{ }^{\dagger} \\
\text { Pressure } n=105\end{array}$ & Significance $^{\dagger \dagger}$ \\
\hline \multicolumn{5}{|l|}{ Family history of diabetes } \\
\hline No & $240(32.1)$ & $207(32.2)$ & $33(31.4)$ & \multirow{2}{*}{$p=0.87$} \\
\hline Yes & $507(67.9)$ & $435(67.8)$ & $72(68.6)$ & \\
\hline \multirow{2}{*}{\multicolumn{5}{|c|}{$\begin{array}{l}\text { Family history of High } \\
\text { blood pressure }\end{array}$}} \\
\hline & & & & \\
\hline No & $267(35.7)$ & $243(37.9)$ & $24(22.6)$ & \multirow{2}{*}{$p=0.002 *$} \\
\hline Yes & $480(64.3)$ & $399(62.1)$ & $82(77.4)$ & \\
\hline \multicolumn{5}{|l|}{ Oil type used in cooking } \\
\hline Vegetable oil & $714(96.4)$ & $613(96.2)$ & $101(97.1)$ & \multirow{2}{*}{$p=0.66$} \\
\hline Animal oil & $27(3.6)$ & $24(3.8)$ & $3(2.9)$ & \\
\hline $\begin{array}{l}\text { Number of Meals not prepared } \\
\text { at home (per week) }\end{array}$ & $2.4 \pm 2.3$ & $2.5 \pm 2.4$ & $2.1 \pm 2.0$ & $p=0.10$ \\
\hline \multicolumn{5}{|l|}{ Smoking Status } \\
\hline Non smoker & $730(97.7)$ & $628(97.8)$ & $102(97.1)$ & \multirow{3}{*}{$p=0.28$} \\
\hline Past smoker & $6(0.8)$ & $6(0.9)$ & $0(0.0)$ & \\
\hline Current smoker & $11(1.5)$ & $8(1.2)$ & $3(2.9)$ & \\
\hline $\begin{array}{l}\text { Exposure to passive Smoking }{ }^{d} \\
\text { (days/week) }\end{array}$ & $1.2 \pm 2.9$ & $1.2 \pm 2.9$ & $1.3 \pm 3.0$ & $p=0.71$ \\
\hline \multicolumn{5}{|l|}{ Physical Activity Level } \\
\hline Low & $416(55.8)$ & $352(54.9)$ & $64(61.0)$ & \multirow{3}{*}{$p=0.41$} \\
\hline Moderate & $162(21.7)$ & $144(22.5)$ & $18(17.1)$ & \\
\hline High & $168(22.5)$ & $145(22.6)$ & $23(21.9)$ & \\
\hline $\begin{array}{l}\text { Total physical activity } \\
\text { (Met-minutes per day) }\end{array}$ & $389.9 \pm 761.9$ & $394.5 \pm 772.7$ & $369.2 \pm 701.5$ & $p=0.75$ \\
\hline $\begin{array}{l}\text { Percent activity from } \\
\text { work }(\%)(n=551)\end{array}$ & $26.2 \pm 37.7$ & $25.5 \pm 37.2$ & $31.7 \pm 40.6$ & $p=0.22$ \\
\hline $\begin{array}{l}\text { Percent activity from } \\
\text { walking }(\%)\end{array}$ & $55.5 \pm 40.8$ & $55.6 \pm 41.1$ & $54.3 \pm 39.8$ & $p=0.80$ \\
\hline $\begin{array}{l}\text { Percent activity form } \\
\text { free time }(\%)\end{array}$ & $18.3 \pm 30.8$ & $18.9 \pm 31.7$ & $14.1 \pm 23.9$ & $p=0.15$ \\
\hline Sedentary time (minutes/day) & $183.6 \pm 168.3$ & $183.0 \pm 164.4$ & $189.5 \pm 191.2$ & $p=0.71$ \\
\hline Body mass index(BMI) $\left(\mathrm{kg} / \mathrm{m}^{2}\right)$ & $29.1 \pm 7.2$ & $28.7 \pm 7.1$ & $30.9 \pm 6.9$ & $p=0.004 *$ \\
\hline Obese $\left(\geqslant 30 \mathrm{~kg} / \mathrm{m}^{2}\right)$ & $279(37.3)$ & $226(35.2)$ & $53(50.0)$ & $p=0.007 *$ \\
\hline
\end{tabular}

$\dagger$ Elevated blood pressure in this study was defined as either systolic pressure $\geqslant 130$ or diastolic pressure $\geqslant 85 \mathrm{~mm} \mathrm{Hg}$;

${ }^{\dagger \dagger} p$-values were derived from $t$ test and Chi Square test for continuous and categorical variables respectively;

a Percentages are within column; b This category includes: no schooling, elementary and intermediate schooling; ${ }^{\mathrm{c}}$ This category includes: private and own business; ${ }^{\mathrm{d}}$ This includes passive smoking from family members and at work; $* \leqslant \leqslant 0.05 ; * * \leqslant 0.001$.

Figure 1 is the scree plot showing eigenvalues for the 15 components derived from the lifestyle and dietary data using PCFA. Examination of the scree plot revealed a clear inflection at the third component (Figure 1). Taken together with the Kaiser criterion of an eigenvalue $>1$, it was deduced that three components/factors ought to be retained. 


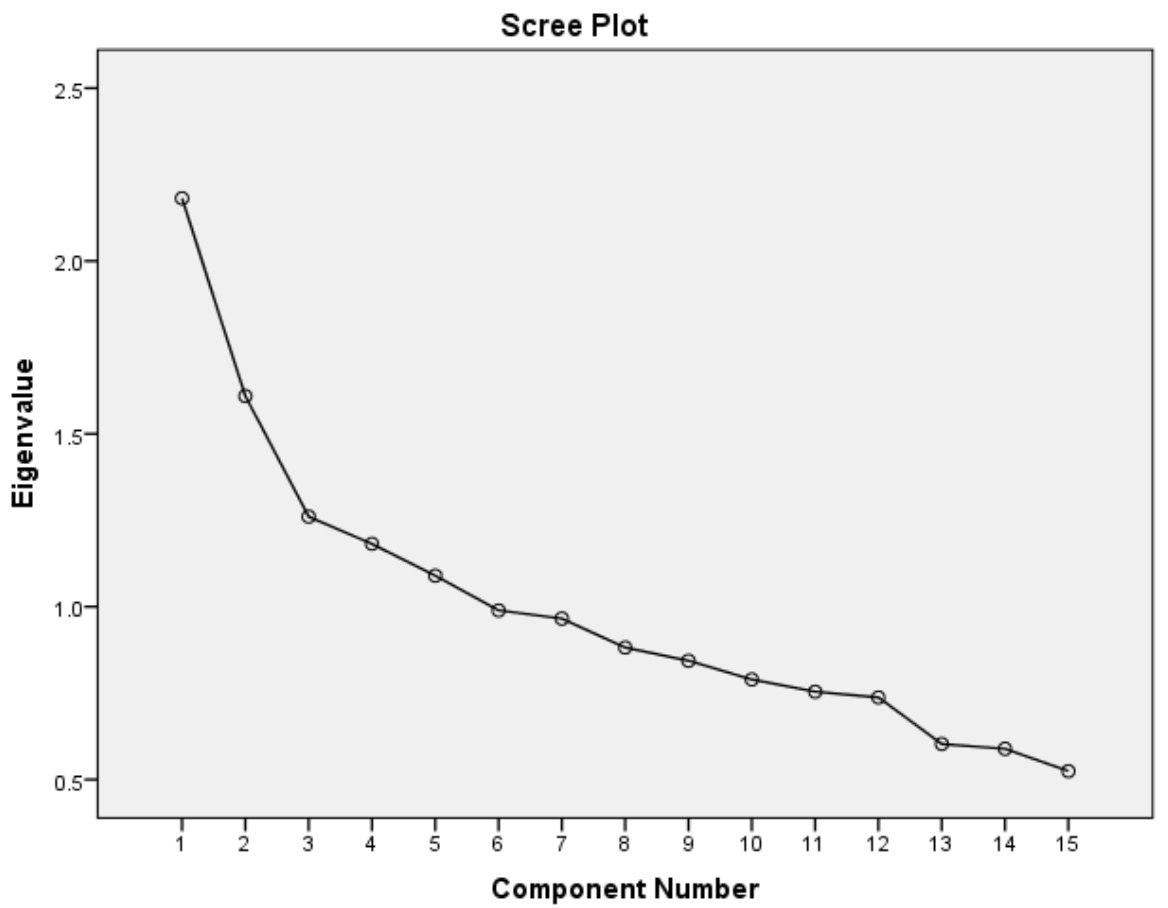

Figure 1. Scree plot showing eigenvalues for the 15 components, extracted in weighted factor analysis of lifestyle and dietary data of study participants $(n=747)$.

Factor loadings and the variance explained by each of the retained three patterns are shown in Table 2 (loadings greater than 0.3 are bolded). Together these patterns explained $34.1 \%$ of the variance ("Healthy": 12.4\%; "Fast food \& smoking": $12.1 \%$ and "Traditional sedentary": 9.6\%). The "Healthy" pattern wascharacterized by a high intake of fruits, beans, natural juices, vegetables, fish, and whole grains. In addition to smoking, the "Fast food \& smoking" pattern was characterized by fast foods, sweetened beverages, sweets and poultry. The "Traditional sedentary" pattern consisted mainly of refined grains, meat and low physical activity. It is important to note that beans loaded on the "Traditional sedentary" pattern (0.26) in addition to the "Fast food \& smoking" pattern (0.56). Whole grains had a high negative loading on the "Traditional sedentary" pattern $(-0.55)$.

Table 2. Weighted factor loading matrix of the three identified lifestyle patterns among a nationally representative sample of Qatari women ${ }^{\text {a }}(n=747)$.

\begin{tabular}{cccc}
\hline & \multicolumn{3}{c}{ Lifestyle Patterns } \\
\cline { 2 - 4 } & Healthy & Fast Food \& Smoking \\
\hline Fruits & $\mathbf{0 . 6 8}$ & -0.20 & \\
Beans & $\mathbf{0 . 5 6}$ & & 0.27 \\
Natural juices & $\mathbf{0 . 5 5}$ & & \\
Vegetables & $\mathbf{0 . 4 4}$ & & -0.21 \\
Fish & $\mathbf{0 . 4 4}$ & & 0.21 \\
Dairy & 0.24 & $\mathbf{0 . 7 8}$ & \\
Fast foods & & $\mathbf{0 . 6 3}$ & \\
Sweetened beverages & &
\end{tabular}


Table 2. Cont.

\begin{tabular}{cccc}
\hline & \multicolumn{3}{c}{ Lifestyle Patterns } \\
\cline { 2 - 4 } & Healthy & Fast Food \& Smoking \\
\hline Sweets & $\mathbf{0 . 5 4}$ \\
Smoking & $\mathbf{0 . 3 9}$ & \\
Poultry & $\mathbf{0 . 3 4}$ & $\mathbf{0 . 7 4}$ \\
Refined grains & 0.22 & $-\mathbf{0 . 5 5}$ \\
Whole grains & $\mathbf{0 . 3 2}$ & -0.21 & $-\mathbf{0 . 4 3}$ \\
Physical activity (Mets/day) & & & $\mathbf{0 . 3 0}$ \\
Meat & & 12.1 & 9.6 \\
\hline Percent variance explained & 12.4 & & \\
\hline
\end{tabular}

To further characterize the identified patterns, the dietary intakes, physical activity, smoking characteristics of study participants were described for the first and third tertiles of each of the patterns' scores (Table 3). Compared to participants in the first tertile of the "Healthy" pattern, those belonging to the third tertile had significantly higher frequencies (days/week) of consumption of fruits, beans, natural juices, vegetables, fish and sea food, dairy products, and whole grains, and had lower frequencies of consumption of sweetened beverages and poultry. As for the "Fast food \& smoking" pattern, frequencies of consumption of beans, fast food, sweetened beverages, sweets, poultry, refined grains, and meat were higher among subjects in the third tertile compared to those in the first tertile. Fruits, vegetables and whole grains frequencies of consumption were lower among subjects in the third compared to the first tertile of this pattern. Furthermore, a higher proportion of smokers was found among subjects in the third tertile of the "Fast food \& smoking" pattern. Foods/food groups with higher frequency of consumption among subjects in the third as compared to the first tertile of the "Traditional sedentary" pattern were beans, dairy products, sweetened beverages, sweets, poultry, refined grains, and meat. In contrast, lower frequency of consumption was noted for fruits, natural juices, vegetables, fish and sea food, fast food and whole grains. Though no difference in physical activity was noted for any of the first two patterns, subjects belonging to third tertile of the "Traditional sedentary" pattern had significantly lower levels of physical activity compared to those belonging to the first tertile (Table 3).

Table 4 displays the association of the derived lifestyle patterns with elevated BP as evaluated by multivariate logistic regression analyses. After adjustment for socio-demographic characteristics and BMI, the results showed that subjects belonging to the second tertile of the "Fast food \& smoking" pattern had a two-fold increase in the odds of elevated BP compared to those in the first tertile (Odds Ratio (OR): 2.1, 95\% CI: 1.4-3.3). A similar association was observed for subjects in the third compared to the first tertile of this pattern however the odds did not reach significance. The small number of smokers in the study sample may not have provided enough power to detect a significant association in the third tertile. Furthermore, a gradual increase in the odds of elevated BP was observed with a higher adherence to the "Traditional sedentary" pattern reaching OR: 2.2, 95\% CI 1.3-3.7 for the third compared to the first tertile of this pattern ( $p$ for trend $<0.05$ ) (Table 4). 
Table 3. Weighted dietary intake, smoking, and physical activity of study participants by tertiles of the three identified patterns' scores ${ }^{\text {a }}$ $(n=747)$.

\begin{tabular}{|c|c|c|c|c|c|c|}
\hline \multirow{2}{*}{ Factor Items } & \multicolumn{2}{|c|}{ Healthy } & \multicolumn{2}{|c|}{ Fast Food \& Smoking } & \multicolumn{2}{|c|}{ Traditional Sedentary } \\
\hline & 1st Tertile & 3rd Tertile & 1st Tertile & 3rd Tertile & 1st Tertile & 3rd Tertile \\
\hline \multicolumn{7}{|c|}{ Mean \pm SD } \\
\hline Fruits (days/week) & $1.2 \pm 1.4$ & $5.1 \pm 2.4 * *$ & $3.6 \pm 2.7$ & $2.3 \pm 2.3 * *$ & $3.5 \pm 2.7$ & $2.7 \pm 2.3 *$ \\
\hline Beans (days/week) & $0.8 \pm 0.9$ & $2.7 \pm 2.1 * *$ & $1.3 \pm 1.4$ & $2.0 \pm 2.1 * *$ & $1.2 \pm 1.4$ & $2.1 \pm 2.0 * *$ \\
\hline Natural juice(days/week) & $1.9 \pm 2.0$ & $5.3 \pm 2.3 * *$ & $3.4 \pm 2.7$ & $3.5 \pm 2.7$ & $3.8 \pm 2.8$ & $3.0 \pm 2.5 *$ \\
\hline Vegetables (days/week) & $4.0 \pm 2.7$ & $6.5 \pm 1.4 * *$ & $5.7 \pm 2.2$ & $5.0 \pm 2.5 *$ & $5.5 \pm 2.3$ & $5.4 \pm 2.3$ \\
\hline Fish and sea food (days/week) & $0.8 \pm 0.8$ & $2.2 \pm 1.6 * *$ & $1.6 \pm 1.3$ & $1.3 \pm 1.3 *$ & $1.7 \pm 1.5$ & $1.1 \pm 1.1 * *$ \\
\hline Dairy products (days/week) & $5.4 \pm 2.5$ & $6.2 \pm 1.8 * *$ & $5.9 \pm 2.1$ & $5.9 \pm 2.2$ & $5.5 \pm 2.4$ & $6.3 \pm 1.7 * *$ \\
\hline Fast food (days/week) & $1.7 \pm 1.9$ & $1.9 \pm 2.0$ & $0.6 \pm 0.8$ & $3.6 \pm 2.3 * *$ & $1.9 \pm 2.2$ & $1.3 \pm 1.4 * *$ \\
\hline Sweetened beverages(days/week) & $2.9 \pm 2.9$ & $2.2 \pm 2.7 *$ & $0.6 \pm 1.2$ & $5.1 \pm 2.6 * *$ & $2.2 \pm 2.7$ & $2.4 \pm 2.7 *$ \\
\hline Sweets (days/week) & $4.3 \pm 2.8$ & $4.2 \pm 2.6$ & $2.4 \pm 2.3$ & $5.9 \pm 1.9 * *$ & $3.9 \pm 2.7$ & $4.7 \pm 2.6 *$ \\
\hline \multicolumn{7}{|l|}{ Smoking Status ${ }^{\text {b }}$} \\
\hline Non smoker & $239(97.2)$ & $229(99.1)$ & $259(100.0)$ & $205(94.0) * *$ & $233(94.7)$ & $248(100.0) * *$ \\
\hline Past smoker & $1(0.4)$ & $2(0.9)$ & $0(0.0)$ & $10(4.6)$ & $3(1.2)$ & $0(0)$ \\
\hline Current smoker & $6(2.4)$ & $0(0.0)$ & $0(0.0)$ & $3(1.4)$ & $10(4.1)$ & $0(0)$ \\
\hline Poultry(days/week) & $5.4 \pm 2.2$ & $4.7 \pm 2.1 *$ & $4.0 \pm 2.3$ & $5.9 \pm 1.8 * *$ & $4.4 \pm 2.3$ & $5.6 \pm 2.0 * *$ \\
\hline Refined grains (days/week) & $5.6 \pm 2.4$ & $5.2 \pm 2.5$ & $4.7 \pm 2.8$ & $5.8 \pm 2.1 * *$ & $2.9 \pm 2.5$ & $7.0 \pm 0.2 * *$ \\
\hline Whole grains (days/week) & $0.9 \pm 1.9$ & $2.8 \pm 2.9 * *$ & $2.6 \pm 2.9$ & $1.4 \pm 2.3 * *$ & $4.0 \pm 3.0$ & $0.4 \pm 1.1 * *$ \\
\hline Total physical activity (Met-minutes per day) & $450 \pm 770$ & $372.3 \pm 672.9$ & $386.0 \pm 677.9$ & $463.5 \pm 844.9$ & $627.5 \pm 1054.0$ & $203.4 \pm 429.0 * *$ \\
\hline Meat (days/week) & $1.3 \pm 1.4$ & $2.0 \pm 1.6 * *$ & $1.4 \pm 1.3$ & $1.9 \pm 1.8 *$ & $1.2 \pm 1.4$ & $2.1 \pm 1.8 * *$ \\
\hline
\end{tabular}

${ }^{\text {a }}$ Intake of the various food groups referred to frequency of consumption as expressed by number of days per week the food/food group was consumed;

${ }^{\mathrm{b}}$ For smoking the numbers represent $n(\%) ; * p \leqslant 0.05 ; * * p \leqslant 0.001$. 
Table 4. Weighted odds ratio and their 95\% Confidence Interval (CI) for the association of the identified lifestyle patterns with elevated blood pressure in the study population $(n=747)$.

\begin{tabular}{cccc}
\hline & \multicolumn{3}{c}{ Dietary Patterns } \\
\cline { 2 - 4 } & Healthy & Fast Food \& Smoking & Traditional Sedentary \\
\hline 1st tertile & Ref. & Age adjusted model \\
2nd tertile & $1.3(0.8-2.1)$ & $\mathbf{2 . 1}(\mathbf{1 . 3}-\mathbf{3 . 2})$ & Ref. \\
3rd tertile & $1.6(0.9-2.5)$ & $1.2(0.7-2.0)$ & $2.1(1.2-3.5)$ \\
\hline & & Multivariate model 2 a & $\mathbf{2 . 2}(\mathbf{1 . 3}-\mathbf{3 . 7})$ \\
\hline 1st tertile & Ref. & Ref. & Ref. \\
2nd tertile & $1.3(0.8-2.2)$ & $\mathbf{2 . 1}(\mathbf{1 . 4 - 3 . 3})$ & $\mathbf{2 . 0}(\mathbf{1 . 2 - 3 . 5})$ \\
3rd tertile & $1.4(0.9-2.2)$ & $1.1(0.7-2.0)$ & $\mathbf{2 . 2}(\mathbf{1 . 3}-\mathbf{3 . 7})$ \\
\hline
\end{tabular}

a This model is adjusted for age, education, marital status, parental consanguinity, family history of blood pressure, number of meals not eaten at home, exposure to passive smoking and Body mass index (BMI).

Multivariate logistic regression models were used in order to determine the correlates of each of the lifestyle patterns. In each of the models, adherence to the lifestyle pattern (belonging to the third tertile $v s$. second and first tertiles) was the outcome with all socio-demographic and lifestyle characteristics as independent variables. Results showed that a higher education level was associated with the "Healthy" pattern (OR: 2.0, 95\% CI: 1.2-3.2). Adherence to the "Fast food \& smoking" pattern was associated with a consumption of a higher number of meals outside home (OR: 1.5, 95\% CI: 1.4-1.7) and a higher exposure to passive smoking (OR: 1.10, 95\% CI: 1.04-1.16). Furthermore, older subjects were less likely to adhere to this pattern (OR: $0.97,95 \% \mathrm{CI}$ : 0.94-0.98). While parental consanguinity was associated with a greater adherence to the "Traditional sedentary" pattern in the study sample (OR: 1.4, 95\% CI: 1.0-1.9), a higher level of education was associated with a lower adherence to this pattern (OR: 0.6, 95\% CI: 0.4-1.0).

\section{Discussion}

To our knowledge, this is the first study to investigate lifestyle patterns and their association with elevated BP. Using data stemming from the National STEPwise survey conducted in Qatar in year 2012, we identified three lifestyle patterns amongst Qatari women of reproductive age, with only the "Fast food \& smoking" and "Traditional sedentary" patterns being associated with increased risk of raised BP. Together, the identified patterns explained $33.7 \%$ of the variance, which falls within the range reported in the literature $(23.5 \%-45 \%)[18,20,29]$. Only a few studies have adopted the lifestyle pattern approach and aimed at investigating the combined effects of food intake and other health-related lifestyle characteristics on disease risk [18,20,29]. A brief description of these studies is presented in the table below (Table 5). 
Table 5. Summary of studies investigating lifestyle factors and their associations with disease among adults.

\begin{tabular}{|c|c|c|c|c|}
\hline Authors's Name & Study Population & Disease Outcome & Lifestyle Factors & Main Findings \\
\hline $\begin{array}{l}\text { Navarro Silvera et al. } \\
(2011)[29] \\
\text { USA }\end{array}$ & $\begin{array}{l}n: 1782 \\
\text { Age: } 30-79 \text { years }\end{array}$ & $\begin{array}{l}\text { Subtypes of } \\
\text { Esophageal and } \\
\text { Gastric Cancer }{ }^{\text {a }}\end{array}$ & $\begin{array}{l}\text { 1. Meat \& nitrate } \\
\text { 2. Fruit \& vegetable } \\
\text { 3. Smoking \& alcohol } \\
\text { 4. Legume \& meat alternate } \\
\text { 5. Gastroesophageal reflux disease (GERD) \& body mass } \\
\text { index (BMI) } \\
\text { 6. Fish \& vitamin C }\end{array}$ & $\begin{array}{l}\text { - "Meat \& nitrate" intake associated with increased risk of EA, } \\
\text { GCA, and OGA } \\
\text { - "Fruit \& vegetable" associated with reduced risk of EA, } \\
\text { ESCC, and GCA } \\
\text { - "Smoking \& alcohol" associated with increased risk of ESCC } \\
\text { - "GERD \& obesity" associated with increased risk of EA } \\
\text { and ESCC } \\
\text { - "Fish \& vitamin C" associated with increased risk of ESCC }\end{array}$ \\
\hline $\begin{array}{l}\text { Steele } \text { et al. } \\
\text { (2014) [18] } \\
\text { Brazil }\end{array}$ & $\begin{array}{l}n: 108,706 \\
\text { Age: } \geqslant 18 \text { years } \\
\text { Sex: } 61.3 \% \text { female }\end{array}$ & N/A & $\begin{array}{l}1 \text { Prudent pattern: regular consumption of fruit and vegetables, } \\
\text { daily fresh-fruit juice, and fat-reduced milk; physical activity } \\
\text { practice, protection against UV radiation, reduced soft } \\
\text { drink consumption } \\
2 \text { Risky pattern: fat-rich meat consumption, excessive alcoholic } \\
\text { beverage intake, current smoking, excess TV watching } \\
\text { (especially in men), regular soft drink consumption } \\
\text { (especially in women) }\end{array}$ & N/A \\
\hline $\begin{array}{l}\text { Waidyatilaka et al. } \\
\text { (2014) [20] } \\
\text { Sri Lanka }\end{array}$ & $\begin{array}{l}n: 617 \\
\text { Age: } 30-45 \text { years } \\
\text { Sex: } 100 \% \text { females }\end{array}$ & $\begin{array}{l}\text { Cardiometabolic risk } \\
\text { variables }{ }^{b}\end{array}$ & $\begin{array}{l}1 \text { Pattern 1: rice and rice flour-based products, pulses, seafood, } \\
\text { fruits, vegetables and green leafy vegetables } \\
2 \text { Pattern 2: wheat, wheat based products and tubers, red meat, and } \\
\text { processed meat } \\
3 \text { Pattern 3: snacks dairy products and poultry, low } \\
\text { physical activity }\end{array}$ & $\begin{array}{l}\text { - Pattern } 1 \text { has no association with dysglycaemic risk } \\
\text { - Patterns } 2 \text { and } 3 \text { positively associated with dysglycaemic risk. } \\
\text { - Pattern } 1 \text { associated with increased HDL and reduced TC } \\
\text { and TAG } \\
\text { - Pattern } 2 \text { associated with increased WC, BMI, FM\% and } \\
\text { hs-CRP and reduced FFM\% and HDL } \\
\text { - Pattern } 3 \text { associated with increased WC, BMI, FM\%, HbAlc, } \\
\text { FBS, TC, TAG, and hs-CRP and reduced FFM\% and HDL }\end{array}$ \\
\hline
\end{tabular}

${ }^{a}$ Subtypes of Esophageal and Gastric Cancer: Esophageal adenocarcinoma (EA), esophageal squamous cell carcinoma (ESCC), gastric cardia adenocarcinoma (GCA), other gastric cancers (OGA); ${ }^{\mathrm{b}}$ Cardiometabolic risk variables: dysglycaemic risk, waist circumference (WC), fat mass percentage (FM\%), fat-free mass percentage (FFM\%), glycosylated $\mathrm{Hb}$ (HbA1c), fasting blood sugar (FBS), total cholesterol (TC), high sensitivity C-reactive protein (hs-CRP), High Density Lipoproteins (HDL); TriAcylGlycerids (TAG). 
As not only diet but also other lifestyle characteristics such as smoking and physical activity are known to increase the risk for elevated BP and other non-communicable diseases (NCDs), the measurement of the combined effect of these variables on disease risk provides valuable information for evidence-based and culturally sensitive primary prevention and health promotion. It was in fact suggested that disease risk increases with the number of unhealthy behaviors such as smoking, unhealthy diet and sedentary behavior [18] and that some of these unhealthy behaviors may interact to produce an even greater risk than if the individual risks are added together [30].

The findings of this study showed that the "Healthy" pattern, characterized by the consumption of plant-based foods (fruits, natural juices, vegetables, beans, whole grains) and fish, was not associated with increased risk of elevated BP in the study population. The "Healthy" pattern of this study shares many characteristics of what is usually described in the literature, as the "Prudent" or "Healthy" dietary pattern [17]. Some of the studies investigating dietary patterns in relation to the risk of hypertension have reported a protective effect from the "Prudent" or "Healthy" pattern [31,32], while others, and in accordance with our findings, have reported a lack of association [33-35]. Available evidence suggests that plant-based dietary patterns, including diets rich in fruits, vegetables, and combination diets such as the DASH (Dietary Approaches to Stop Hypertension), may be associated with BP reductions in both hypertensive and normotensive individuals [36,37]. Plant-based foods are in fact good sources of potassium, magnesium, dietary fiber and anthocyanins, all of which have been suggested to exert beneficial effects on BP regulation [12]. The "Healthy" pattern was also characterized by a higher frequency of fish consumption, which may imply a higher intake of omega 3 fatty acids. Available evidence suggests that high intakes of fish oils from supplements may be associated with BP reduction, while evidence on naturally occurring omega 3 fatty acids from fatty fish is less convincing [12]. This highlights, once more, the importance of adopting a holistic pattern dietary analysis approach, rather than investigating the consumption of individual foods, when looking at factors associated with disease risk [12]. In this context, it is important to note that the fact that the "Healthy" pattern did not load on physical activity may have diluted the protective effects of its dietary components, thus explaining the lack of association between the "Healthy" pattern and BP. In fact, substantial evidence links higher levels of physical to lower risks of hypertension and underlines a dose-dependent inverse relationship between levels of physical activity and BP [11]. The recent guidelines of the American College of Cardiology and the American Heart Association for the reduction of cardiovascular risk, including elevated BP, stress a combination of lifestyle intervention strategies that incorporate higher physical activity levels with healthy dietary patterns emphasizing vegetables, fruits, whole grains, fish, and legumes [11].

The "Fast food \& smoking" pattern, which is characterized by smoking and the consumption of fast foods, sweetened beverages, and sweets, was associated with a two-fold increase in the risk of elevated BP amongst Qatari women of reproductive age, even after adjustment for potential confounders including BMI. As such, our findings demonstrate the synergistic effects of smoking with dietary habits on disease risk. Available evidence suggests that smoking is associated with increased BP, even though a clear causal relationship has not yet been documented. In a prospective cohort study based on the Women's Health Study, smoking was found to be associated with an increased risk of developing hypertension, with the strongest effect being documented among women smoking at least 15 cigarettes per day [38]. The increase in BP in smokers may depend on several factors including (1) the toxic effects of carbon 
monoxide and other smoking-related chemical compounds on the arterial wall; (2) the increase in red blood cell number and blood viscosity-secondary to carbon monoxide exposure [39] and (3) sympathetic and adrenergic stimulation, which is mainly caused by nicotine and its metabolites [40]. In addition to smoking, the "Fast food \& smoking" pattern is also characterized by the consumption of fast food, which may imply a higher intake of salt, saturated fatty acids (SFA) and trans fatty acids (TFA). While high salt intake has been established as a risk factor for hypertension and elevated BP, the relationship between BP and the intakes of SFA and TFA is less conclusive [41-43]. It has been suggested that high SFA intakes may adversely affect vascular function and increase BP by proinflammatory mechanisms within the endothelium [43], while TFA consumption was associated with an impairment of endothelial function, as reflected by a reduction in brachial artery flow-mediated vasodilatation [44]. Higher frequency of consumption of sweets and sugar sweetened beverages (SSBs) was another characteristic of the "Fast food \& smoking" pattern, thus implying a higher intake of sugar. Even though available evidence is conflicting, a recent systematic review and meta-analysis of randomized controlled trials showed that higher intakes of sugars are associated with increased BP levels [45]. High glucose intakes and postprandial hyperglycemia were suggested to impair vascular endothelial function by inducing lipid peroxidation and decreasing Nitric Oxide bioavailability [46]. High fructose intakes have been also mechanistically linked to an impairment of insulin signaling [47], increased lipogenesis [48] and disruption of vascular homeostasis [46,49]. Interestingly, it has been postulated that increased dietary fructose and salt may exert an additive effect on BP elevation [50]. Recent studies have in fact shed new light on the role of dietary fructose in enhancing salt absorption at the levels of the intestine and the kidney, highlighting a possible synergistic effect between fructose and salt in the development of hypertension [50]. Taken together, it can be noted that even though controversy characterizes the associations between individual dietary components and BP, our study shows that a lifestyle pattern in Qatar characterized by smoking coupled with dietary habits that may increase the intake of SFA, TFA, salt and sugar is associated with a two fold increase in elevated BP risk.

In this study, women who were predominantly physically inactive and consumed more meat and refined grains ("Traditional sedentary") had also a significant increase in the risk of elevated BP. Physical inactivity has been repetitively identified as a risk factor for elevated BP and hypertension, with the protective effects of physical activity being documented in prehypertensive as well as hypertensive individuals [51-53]. A recent meta-analysis of 13 prospective cohort studies confirmed an inverse, dose-response association between levels of recreational physical activity and risk for developing hypertension [51,52]. Mechanistically, it was shown that physical activity significantly improves vascular function [54] and that habitual aerobic exercise training improves arterial stiffness [55] as well as endothelium-dependent vasorelaxation through increasing nitric oxide release [54]. The high prevalence of physical inactivity amongst Qatari women does not bode well for the future health profile of the population of Qatar. A higher frequency of red meat consumption was another characteristic of the "Traditional sedentary" pattern. The evidence on the association between meat and BP is controversial. In a prospective cohort of female US health professionals, red meat intake was positively associated with the risk of hypertension [56], while in a cross-sectional study on Dutch adults, meat protein was not found to be associated with incident hypertension [57]. In contrast, Ahhmed and Muguruma (2010) reported that meat protein may play a protective role against hypertension, a role that is mainly mediated by the 
angiotension-converting enzyme inhibitory activity of some of its protein hydorlysates [58]. A recent large prospective cohort of French women showed that while there was no association of unprocessed red meat consumption with hypertension, the consumption of processed red meat was significantly associated with a risk for hypertension [59]. Red meat in general, and processed meat in particular, are major sources of saturated fat and cholesterol, which have been suggested to have detrimental effects on BP control [56,60]. In addition, processed red meat is usually high in salt and contains various preservatives, additives, and other chemicals arising from food processing [56]. The advanced glycation and lipoxidation end products formed during the processing or cooking of red meat may impair insulin activity [61], induce inflammatory mediators [62] and may therefore impact BP regulation [56]. Qatar's STEPwise survey did not differentiate between the intake of processed $v s$. unprocessed meat.

The "Traditional sedentary" pattern is also characterized by a more frequent consumption of refined grains, while loading negatively on whole grains. These characteristic point towards a high glycemic index (GI) dietary pattern. Even though the evidence on the association between GI and BP is conflicting, it is suggested that high GI diets lead to postprandial hyperglycemia, which in turn increases reactive oxygen species and lowers antioxidant concentrations. These changes are associated with increased BP and reduced endothelium-dependent blood flow [63]. It is important to note that the "Traditional sedentary" pattern has also loaded on dairy products, a food group that has been associated with protective effects against hypertension [64], given its unique micronutrient composition (vitamin D, calcium, phosphorous and potassium), its rich array of bioactive lactotripeptides and its low sodium content [64]. However, several large prospective cohort studies reported benefits from consuming low-fat versus whole-fat dairy products $[65,66]$. Dairy fat is primarily saturated fat, including medium and longer chain fatty acids that are atherogenic, which may potentially counter the benefits of dairy consumption [64]. The STEPwise survey conducted in Qatar did not allow differentiation between whole versus low fat varieties of dairy products.

This study has also examined the socio-demographic determinants of the identified lifestyle patterns. Adherence to the "Healthy" pattern was found to be associated with a higher education level. In line with these findings, Steele et al. (2014) showed that, amongst Brazilian adults, the prudent lifestyle pattern was positively associated with the number of schooling years. Higher education levels may in fact be associated with higher nutrition knowledge, an essential precursor to healthy dietary and lifestyle habits [67]. In our study, adherence to the "Fast food \& smoking" pattern was associated with a higher consumption of meals outside home, while older and married women were less likely to adhere to this pattern. Similarly, Steele et al. (2014) showed that adherence to what they termed the "risky pattern", characterized by the consumption of fat-rich meat, excessive alcohol and current smoking habits, was also found to be inversely associated with age. A possible explanation may be that older subjects tend to maintain traditional dietary and lifestyle habits as compared to younger generations who have greater exposure to "fashionable" foods and are more vulnerable to emerging marketing trends [68]. The inverse association between age and adherence to the "Fast food \& smoking" pattern might also reflect a state of nutrition transition, from a "traditional" to a "western" lifestyle pattern, a phenomenon that typically manifests itself in younger age groups as is currently experienced by many countries of the Eastern Mediterranean region [69,70]. As for adherence to the "Traditional sedentary" pattern, it was found to 
be positively associated with parental consanguinity, which suggests that this pattern may be the closest to the traditional Qatari lifestyle pattern.

The present study had several strengths. Using the standardized WHO STEPwise survey approach in data collection and analysis, this study is the first to report on the association between lifestyle patterns and the risk of elevated BP. Its findings are stemming from a nationally representative sample of women of reproductive age, and weighting was performed to correct for the sample distribution. Interviewer errors and inter-observer measurement error in anthropometric assessment and BP measurement were minimized by extensive training of all interviewers to maintain quality of measurements and data collection The Arabic Global Physical Activity Questionnaire (GPAC) was used to assess physical activity, and its scoring followed a standardized approach, as recommended by the WHO. The derivation of lifestyle patterns provides a broader picture of food consumption and lifestyle components as they relate to disease risk, and may thus have more practical applications than the analysis of single foods, nutrients or behaviors.

Findings of this study should, however, be considered in light of the following limitations. First, the study had a cross-sectional design, and thus its findings can mainly be used to infer associations rather than assessing causal relationships. However, to eliminate possible reverse causation, we have excluded participants who reported having hypertension or those who reported dietary changes at the time of BP examinations (including patients with Diabetes). The rationale for the exclusion of participants with known diagnosis of hypertension was based on the fact that these participants might have received lifestyle consultations and have consequently changed their diet, exercise and smoking habits. These changes may dilute the effect of diet on elevated blood pressure and lead to a type II error.

Second, information on portion size was not collected. However, it is important to note that the complex cognitive process of portion size estimation may pose additional challenges to study participants who consume varying portion sizes across meals [71] and may not be always aware of the portion size [72]. Although quantification skills may improve with training and the use of food photograph aids [73], inclusion of portion size questions may increase respondent burden and lead to data omission, and hence contribute only marginally beyond frequency data in improving validity of the dietary assessment tool [74]. Therefore, recent research in this area has focused on the development of non-quantitative dietary questionnaires (without collection of portion size information) as targeted dietary assessment tools to rank individuals by intake of specific food groups or dietary patterns rather than providing absolute values for foods and/or nutrients [75]. Besides providing information on usual intakes of a particular food or food groups of interest, such questionnaires are particularly useful in identifying dietary patterns at the population level [76]. Third, salt intake, which is an important factor influencing BP, was not assessed in the present study. Most studies investigating the association between dietary patterns and BP did not examine salt intake, since valid assessment of salt intake necessitates the collection of 24-hour urine samples or the adoption of robust dietary assessment tools [77]. Lastly, it remains important to note that no information on alcohol intake was obtained, the latter being a possible risk factor for elevated BP. For culture-specific reasons, this information was not collected in the Qatar STEPwise survey. 


\section{Conclusions}

This study documented a significant positive association between elevated BP and specific Qatari lifestyle patterns amongst women of reproductive age. More specifically, the "Fast food \& smoking" pattern (smoking, and consumption of fast foods, sweetened beverages, and sweets) and the "Traditional sedentary" pattern (physical inactivity and the consumption of meat and refined grains) were associated with an approximately two-fold increase in the risk of elevated BP in this age group. These findings highlight the synergistic effects that diet and other lifestyle components may have on disease risk.

The results of this study therefore support the recommendations of the Eighth Report of the Joint National Committee on Prevention, Detection, Evaluation, and Treatment of High Blood Pressure (JNC 8) and the European Society of Hypertension/European Society of Hypertension of Cardiology, which state that appropriate lifestyle interventions, including increased physical activity and the adoption of healthy dietary patterns, should be fostered for the prevention and treatment of hypertension [51]. Qatar launched, in April 2015, the Qatar Dietary Guidelines, which aim at directing both individual behavior change and the development of health and food policies in Qatar [78]. It would be of value to revisit the guidelines in light of the information provided in this study and investigate the impact of these guidelines on dietary habits of the population in general and of Qatari women in particular.

\section{Acknowledgments}

The study was funded by the Supreme Council of Health, Doha, Qatar. The authors wish to thank the Ministry of Development Planning and Statistics, Hamad Medical Corporation (HMC), Primary Health Care Corporation (PHCC) and Qatar Diabetes Association (QDA) for their firm commitment and work. The authors express their deep gratitude to all survey team members as well as to all the subjects who participated in this study.

\section{Author Contributions}

M.A.T. conceptualized the study, supervised all related activities and evaluated its significance to Qatar; A.A.T. contributed to study design and, in her capacity as a WHO focal point, coordinated various aspects of the study; W.A.C. supervised data collection and contributed to the interpretation of the data; B.A.M. managed and supervised data collection and coordinated field work; S.H.K. supervised data management and coding; A.H.B. led the narrative reporting of the 2012 Qatar WHO STEPwise survey; N.H. contributed to the conceptualization of the study and to the interpretation of the data; L.N and F.N conducted data analysis and wrote the manuscript. All authors read and approved the final manuscript and critically reviewed the manuscript.

\section{Conflicts of Interest}

The authors declare no conflict of interest. 


\section{References}

1. Lim, S.S.; Vos, T.; Flaxman, A.D.; Danaei, G.; Shibuya, K.; Adair-Rohani, H.; AlMazroa, M.A.; Amann, M.; Anderson, H.R.; Andrews, K.G. A comparative risk assessment of burden of disease and injury attributable to 67 risk factors and risk factor clusters in 21 regions, 1990-2010: A systematic analysis for the Global Burden of Disease Study 2010. Lancet 2013, 380, 2224-2260. [CrossRef]

2. World Health Organization. A Global Brief on Hypertension: Silent Killer, Global Public Health Crisis; World Health Organization: Geneva, Switzerland, 2013.

3. Raised Blood Pressure (SBP $\geqslant 140$ or DBP $\geqslant 90$ ): Data by WHO Region. Available online: http://apps.who.int/gho/data/view.main.2540?lang=en (accessed on 5 May 2015).

4. Kearney, P.M.; Whelton, M.; Reynolds, K.; Muntner, P.; Whelton, P.K.; He, J. Global burden of hypertension: Analysis of worldwide data. Lancet 2005, 365, 217-223. [CrossRef]

5. World Health Organization. World Health Survey; World Health Organization: Geneva, Switzerland, 2006.

6. Haj Bakri, A.; Al-Thani, A. Chronic Disease Risk Factor Surveillance: Qatar STEPS Report 2012; Supreme Council of Health: Doha, Qatar, 2013.

7. Bramham, K.; Parnell, B.; Nelson-Piercy, C.; Seed, P.T.; Poston, L.; Chappell, L.C. Chronic hypertension and pregnancy outcomes: Systematic review and meta-analysis. BMJ 2014, 348. Available online: http://www.bmj.com/content/348/bmj.g2301 (accessed on 4 May 2015). [CrossRef] [PubMed]

8. Lovgren, T.R.; Galan, H.L. Preeclampsia: The Compromised Fetus, the Compromised Mother. In Anesthesia and the Fetus; Wiley-Blackwell: Oxford, UK, 2013; pp. 303-314.

9. Ramakrishnan, A.; Lee, L.J.; Mitchell, L.E.; Agopian, A.J. Maternal Hypertension during Pregnancy and the Risk of Congenital Heart Defects in Offspring: A Systematic Review and Meta-analysis. Pediatr. Cardiol. 2015. Available online: http://link.springer.com/article/10.1007\%2Fs00246-015-1182-9 (accessed on 11 May 2015). [CrossRef] [PubMed]

10. De Marco, M.; de Simone, G.; Roman, M.J.; Chinali, M.; Lee, E.T.; Russell, M.; Howard, B.V.; Devereux, R.B. Cardiovascular and metabolic predictors of progression of prehypertension into hypertension: The Strong Heart Study. Hypertension 2009, 54, 974-980. [CrossRef] [PubMed]

11. Eckel, R.H.; Jakicic, J.M.; Ard, J.D.; de Jesus, J.M.; Houston Miller, N.; Hubbard, V.S.; Lee, I.M.; Lichtenstein, A.H.; Loria, C.M.; Millen, B.E.; et al. 2013 AHA/ACC guideline on lifestyle management to reduce cardiovascular risk: A report of the American College of Cardiology/American Heart Association Task Force on Practice Guidelines. J. Am. Coll. Cardiol. 2014, 63, 2960-2984. [CrossRef]

12. Bazzano, L.A.; Green, T.; Harrison, T.N.; Reynolds, K. Dietary approaches to prevent hypertension. Curr. Hypertens. Rep. 2013, 15, 694-702. [CrossRef] [PubMed]

13. Teunissen-Beekman, K.F.; van Baak, M.A. The role of dietary protein in blood pressure regulation. Curr. Opin. Lipidol. 2013, 24, 65-70. [CrossRef] [PubMed] 
14. Streppel, M.T.; Arends, L.R.; van't Veer, P.; Grobbee, D.E.; Geleijnse, J.M. Dietary fiber and blood pressure: A meta-analysis of randomized placebo-controlled trials. Arch. Intern. Med. 2005, 165, 150-156. [CrossRef] [PubMed]

15. Jacques, P.F.; Tucker, K.L. Are dietary patterns useful for understanding the role of diet in chronic disease? Am. J. Clin. Nutr. 2001, 73, 1-2. [PubMed]

16. Jiang, J.; Liu, M.; Parvez, F.; Wang, B.; Wu, F.; Eunus, M.; Bangalore, S.; Ahmed, A.; Islam, T.; Rakibuz-Zaman, M. Association of major dietary patterns and blood pressure longitudinal change in Bangladesh. J. Hypertens. 2015, 33, 1193-1200. [CrossRef] [PubMed]

17. Shi, Z.; Taylor, A.W.; Atlantis, E.; Wittert, G.A. Empirically derived dietary patterns and hypertension. Curr. Nutr. Rep. 2012, 1, 73-86. [CrossRef]

18. Steele, E.M.; Claro, R.M.; Monteiro, C.A. Behavioural patterns of protective and risk factors for non-communicable diseases in Brazil. Public Health Nutr. 2014, 17, 369-375. [CrossRef] [PubMed]

19. Gubbels, J.S.; Kremers, S.P.; Stafleu, A.; Goldbohm, R.A.; de Vries, N.K.; Thijs, C. Clustering of energy balance-related behaviors in 5-year-old children: Lifestyle patterns and their longitudinal association with weight status development in early childhood. Int. J. Behav. Nutr. Phys. Act. 2012, 9, 77. Available online: http://www.ncbi.nlm.nih.gov/pmc/articles/PMC3441251/pdf/14795868-9-77.pdf (accessed on 6 May 2015). [CrossRef] [PubMed]

20. Waidyatilaka, I.; de Silva, A.; de Lanerolle-Dias, M.; Wickremasinghe, R.; Atukorala, S.; Somasundaram, N.; Lanerolle, P. Lifestyle patterns and dysglycaemic risk in urban Sri Lankan women. Br. J. Nutr. 2014, 112, 952-957. [CrossRef] [PubMed]

21. Final Results of Census 2010. Available online: http://www.qsa.gov.qa/qatarcensus/Census_ Results.aspx (accessed on 8 May 2015).

22. Global Physical Activity Surveillance. Available online: http://www.who.int/chp/steps/GPAQ/en/ (accessed on 20 March 2015).

23. World Health Organization. In Global Physical Activity Questionnaire (GPAQ) Analysis Guide; World Health Organization: Geneva, Switzerland, 2012.

24. Hallal, P.C.; Andersen, L.B.; Bull, F.C.; Guthold, R.; Haskell, W.; Ekelund, U. Global physical activity levels: Surveillance progress, pitfalls, and prospects. Lancet 2012, 380, 247-257. [CrossRef]

25. Wong, J.E.; Parnell, W.R.; Black, K.E.; Skidmore, P.M. Reliability and relative validity of a food frequency questionnaire to assess food group intakes in New Zealand adolescents. Nutr. J. 2012, 11. [CrossRef] [PubMed]

26. Expert Panel on Detection Evaluation and Treatment of High Blood Cholesterol in Adults. Executive summary of the third report of the national cholesterol education program (NCEP) expert panel on detection, evaluation, and treatment of high blood cholesterol in adults (adult treatment panel III). JAMA 2001, 285, 2486-2497. 
27. Alberti, K.G.; Eckel, R.H.; Grundy, S.M.; Zimmet, P.Z.; Cleeman, J.I.; Donato, K.A.; Fruchart, J.C.; James, W.P.; Loria, C.M.; Smith, S.C., Jr. Harmonizing the metabolic syndrome: A joint interim statement of the International Diabetes Federation Task Force on Epidemiology and Prevention; National Heart, Lung, and Blood Institute; American Heart Association; World Heart Federation; International Atherosclerosis Society; and International Association for the Study of Obesity. Circulation 2009, 120, 1640-1645. [PubMed]

28. IBM Corp. IBM SPSS Statistics for Windows, 14.1; IBM Corp.: Armonk, NY, USA, 2010.

29. Navarro Silvera, S.A.; Mayne, S.T.; Risch, H.A.; Gammon, M.D.; Vaughan, T.; Chow, W.H.; Dubin, J.A.; Dubrow, R.; Schoenberg, J.; Stanford, J.L.; et al. Principal component analysis of dietary and lifestyle patterns in relation to risk of subtypes of esophageal and gastric cancer. Ann. Epidemiol. 2011, 21, 543-550. [CrossRef] [PubMed]

30. Meng, L.; Maskarinec, G.; Lee, J.; Kolonel, L.N. Lifestyle factors and chronic diseases: Application of a composite risk index. Prev. Med. 1999, 29, 296-304. [CrossRef] [PubMed]

31. Wang, D.; He, Y.; Li, Y.; Luan, D.; Yang, X.; Zhai, F.; Ma, G. Dietary patterns and hypertension among Chinese adults: A nationally representative cross-sectional study. BMC Public Health 2011, 11, 1-10. Available online: http://www.biomedcentral.com/1471-2458/11/925 (accessed on 8 May 2015). [CrossRef] [PubMed]

32. Sadakane, A.; Tsutsumi, A.; Gotoh, T.; Ishikawa, S.; Ojima, T.; Kario, K.; Nakamura, Y.; Kayaba, K. Dietary patterns and levels of blood pressure and serum lipids in a Japanese population. J. Epidemiol. 2008, 18, 58-67. [CrossRef] [PubMed]

33. Oliveira, A.; Rodriguez-Artalejo, F.; Gaio, R.; Santos, A.C.; Ramos, E.; Lopes, C. Major habitual dietary patterns are associated with acute myocardial infarction and cardiovascular risk markers in a southern European population. J. Am. Diet. Assoc. 2011, 111, 241-250. [CrossRef] [PubMed]

34. Villegas, R.; Kearney, P.M.; Perry, I.J. The cumulative effect of core lifestyle behaviours on the prevalence of hypertension and dyslipidemia. BMC Public Health 2008, 8, 210. [CrossRef] [PubMed]

35. Qin, Y.; Melse-Boonstra, A.; Pan, X.; Zhao, J.; Yuan, B.; Dai, Y.; Zhou, M.; Geleijnse, J.M.; Kok, F.J.; Shi, Z. Association of dietary pattern and body weight with blood pressure in Jiangsu Province, China. BMC Public Health 2014, 14, 948. [CrossRef] [PubMed]

36. Berkow, S.E.; Barnard, N.D. Blood pressure regulation and vegetarian diets. Nutr. Rev. 2005, 63, 1-8. [CrossRef] [PubMed]

37. Wang, L.; Manson, J.E.; Gaziano, J.M.; Buring, J.E.; Sesso, H.D. Fruit and vegetable intake and the risk of hypertension in middle-aged and older women. Am. J. Hypertens. 2012, 25, 180-189. [CrossRef] [PubMed]

38. Bowman, T.S.; Gaziano, J.M.; Buring, J.E.; Sesso, H.D. A prospective study of cigarette smoking and risk of incident hypertension in women. J. Am. Coll. Cardiol. 2007, 50, 2085-2092. [CrossRef] [PubMed]

39. Levenson, J.; Simon, A.C.; Cambien, F.A.; Beretti, C. Cigarette smoking and hypertension. Factors independently associated with blood hyperviscosity and arterial rigidity. Arteriosclerosis 1987, 7, 572-577. [CrossRef] [PubMed] 
40. Leone, A. Smoking and hypertension: Independent or additive effects to determining vascular damage? Curr. Vasc. Pharmacol. 2011, 9, 585-593. [CrossRef] [PubMed]

41. World Health Organization. Guideline: Sodium Intake for Adults and Children; World Health Organization: Geneva, Switzerland, 2012.

42. European Food Safety Authority. Opinion of the scientific panel on dietetic products, nutrition and allergies on a request from the commission related to the presence of trans fatty acids in foods and the effect on human health of the consumption of trans fatty acids. EFSA J. 2004, 81, 1-49.

43. Hall, W.L. Dietary saturated and unsaturated fats as determinants of blood pressure and vascular function. Nutr. Res. Rev. 2009, 22, 18-38. [CrossRef] [PubMed]

44. De Roos, N.M.; Bots, M.L.; Katan, M.B. Replacement of dietary saturated fatty acids by trans fatty acids lowers serum HDL cholesterol and impairs endothelial function in healthy men and women. Arterioscler. Thromb. Vasc. Biol. 2001, 21, 1233-1237. [CrossRef] [PubMed]

45. Te Morenga, L.A.; Howatson, A.J.; Jones, R.M.; Mann, J. Dietary sugars and cardiometabolic risk: Systematic review and meta-analyses of randomized controlled trials of the effects on blood pressure and lipids. Am. J. Clin. Nutr. 2014, 100, 65-79. [CrossRef] [PubMed]

46. Mah, E.; Noh, S.K.; Ballard, K.D.; Matos, M.E.; Volek, J.S.; Bruno, R.S. Postprandial hyperglycemia impairs vascular endothelial function in healthy men by inducing lipid peroxidation and increasing asymmetric dimethylarginine:arginine. J. Nutr. 2011, 141, 1961-1968. [CrossRef] [PubMed]

47. Stanhope, K.L.; Schwarz, J.M.; Keim, N.L.; Griffen, S.C.; Bremer, A.A.; Graham, J.L.; Hatcher, B.; Cox, C.L.; Dyachenko, A.; Zhang, W. Consuming fructose-sweetened, not glucose-sweetened, beverages increases visceral adiposity and lipids and decreases insulin sensitivity in overweight/obese humans. J. Clin. Investig. 2009, 119, 1322-1334. [CrossRef] [PubMed]

48. Samuel, V.T. Fructose induced lipogenesis: From sugar to fat to insulin resistance. Trends Endocrinol. Metab. 2011, 22, 60-65. [CrossRef] [PubMed]

49. Siervo, M.; Montagnese, C.; Mathers, J.C.; Soroka, K.R.; Stephan, B.C.; Wells, J.C. Sugar consumption and global prevalence of obesity and hypertension: An ecological analysis. Public Health Nutr. 2014, 17, 587-596. [CrossRef] [PubMed]

50. Madero, M.; Perez-Pozo, S.E.; Jalal, D.; Johnson, R.J.; Sanchez-Lozada, L.G. Dietary fructose and hypertension. Curr. Hypertens. Rep. 2011, 13, 29-35. [CrossRef] [PubMed]

51. Kokkinos, P. Cardiorespiratory fitness, exercise, and blood pressure. Hypertension 2014, 64, 1160-1164. [CrossRef] [PubMed]

52. Huai, P.; Xun, H.; Reilly, K.H.; Wang, Y.; Ma, W.; Xi, B. Physical activity and risk of hypertension: A meta-analysis of prospective cohort studies. Hypertension 2013, 62, 1021-1026. [CrossRef] [PubMed]

53. Brook, R.D.; Appel, L.J.; Rubenfire, M.; Ogedegbe, G.; Bisognano, J.D.; Elliott, W.J.; Fuchs, F.D.; Hughes, J.W.; Lackland, D.T.; Staffileno, B.A.; et al. Beyond medications and diet: Alternative approaches to lowering blood pressure. Hypertension 2013, 61, 1360-1383. [CrossRef] [PubMed]

54. Pal, S.; Radavelli-Bagatini, S.; Ho, S. Potential benefits of exercise on blood pressure and vascular function. J. Am. Soc. Hypertens. 2013, 7, 494-506. [CrossRef] [PubMed] 
55. Seals, D.R.; Moreau, K.L.; Gates, P.E.; Eskurza, I. Modulatory influences on ageing of the vasculature in healthy humans. Exp. Gerontol. 2006, 41, 501-507. [CrossRef] [PubMed]

56. Wang, L.; Manson, J.E.; Buring, J.E.; Sesso, H.D. Meat intake and the risk of hypertension in middle-aged and older women. J. Hypertens. 2008, 26, 215-222. [CrossRef] [PubMed]

57. Altorf-van der Kuil, W.; Engberink, M.F.; Geleijnse, J.M.; Boer, J.M.; Monique Verschuren, W.M. Sources of dietary protein and risk of hypertension in a general Dutch population. Br. J. Nutr. 2012, 108, 1897-1903. [CrossRef] [PubMed]

58. Ahhmed, A.M.; Muguruma, M. A review of meat protein hydrolysates and hypertension. Meat Sci. 2010, 86, 110-118. [CrossRef] [PubMed]

59. Lajous, M.; Bijon, A.; Fagherazzi, G.; Rossignol, E.; Boutron-Ruault, M.C.; Clavel-Chapelon, F. Processed and unprocessed red meat consumption and hypertension in women. Am. J. Clin. Nutr. 2014, 100, 948-952. [CrossRef] [PubMed]

60. Stamler, J.; Liu, K.; Ruth, K.J.; Pryer, J.; Greenland, P. Eight-year blood pressure change in middle-aged men: Relationship to multiple nutrients. Hypertension 2002, 39, 1000-1006. [CrossRef] [PubMed]

61. Peppa, M.; Goldberg, T.; Cai, W.; Rayfield, E.; Vlassara, H. Glycotoxins: A missing link in the "relationship of dietary fat and meat intake in relation to risk of type 2 diabetes in men". Diabetes Care 2002, 25, 1898-1899. [CrossRef] [PubMed]

62. Vlassara, H.; Cai, W.; Crandall, J.; Goldberg, T.; Oberstein, R.; Dardaine, V.; Peppa, M.; Rayfield, E.J. Inflammatory mediators are induced by dietary glycotoxins, a major risk factor for diabetic angiopathy. Proc. Natl. Acad. Sci. USA 2002, 99, 15596-15601. [CrossRef] [PubMed]

63. Title, L.M.; Cummings, P.M.; Giddens, K.; Nassar, B.A. Oral glucose loading acutely attenuates endothelium-dependent vasodilation in healthy adults without diabetes: An effect prevented by vitamins C and E. J. Am. Coll. Cardiol. 2000, 36, 2185-2191. [CrossRef]

64. McGrane, M.M.; Essery, E.; Obbagy, J.; Lyon, J.; MacNeil, P.; Spahn, J.; van Horn, L. Dairy consumption, blood pressure, and risk of hypertension: An evidence-based review of recent literature. Curr. Cardiovasc. Risk Rep. 2011, 5, 287-298. [CrossRef] [PubMed]

65. Toledo, E.; Delgado-Rodriguez, M.; Estruch, R.; Salas-Salvado, J.; Corella, D.; Gomez-Gracia, E.; Fiol, M.; Lamuela-Raventos, R.M.; Schroder, H.; Aros, F.; et al. Low-fat dairy products and blood pressure: Follow-up of 2290 older persons at high cardiovascular risk participating in the PREDIMED study. Br. J. Nutr. 2009, 101, 59-67. [CrossRef] [PubMed]

66. Alonso, A.; Beunza, J.J.; Delgado-Rodriguez, M.; Martinez, J.A.; Martinez-Gonzalez, M.A. Low-fat dairy consumption and reduced risk of hypertension: The Seguimiento Universidad de Navarra (SUN) cohort. Am. J. Clin. Nutr. 2005, 82, 972-979. [PubMed]

67. Darmon, N.; Drewnowski, A. Does social class predict diet quality? Am. J. Clin. Nutr. 2008, 87, 1107-1117. [PubMed]

68. Hu, E.A.; Toledo, E.; Diez-Espino, J.; Estruch, R.; Corella, D.; Salas-Salvado, J.; Vinyoles, E.; Gomez-Gracia, E.; Aros, F.; Fiol, M.; et al. Lifestyles and risk factors associated with adherence to the Mediterranean diet: A baseline assessment of the PREDIMED trial. PLoS ONE 2013, 8, e60166. Available online: http://journals.plos.org/plosone/article?id=10.1371/journal.pone.0060166 (accessed on 15 May 2015). [CrossRef] [PubMed] 
69. Naja, F.; Nasreddine, L.; Itani, L.; Chamieh, M.C.; Adra, N.; Sibai, A.M.; Hwalla, N. Dietary patterns and their association with obesity and sociodemographic factors in a national sample of Lebanese adults. Public Health Nutr. 2011, 14, 1570-1578. [CrossRef] [PubMed]

70. Nasreddine, L.; Hwalla, N.; Sibai, A.; Hamze, M.; Parent-Massin, D. Food consumption patterns in an adult urban population in Beirut, Lebanon. Public Health Nutr. 2006, 9, 194-203. [CrossRef] [PubMed]

71. Watanabe, M.; Yamaoka, K.; Yokotsuka, M.; Adachi, M.; Tango, T. Validity and reproducibility of the FFQ (FFQW82) for dietary assessment in female adolescents. Public Health Nutr. 2011, 14, 297-305. [CrossRef] [PubMed]

72. Livingstone, M.B.; Robson, P.J. Measurement of dietary intake in children. Proc. Nutr. Soc. 2000, 59, 279-293. [CrossRef] [PubMed]

73. Foster, E.; Matthews, J.N.; Nelson, M.; Harris, J.M.; Mathers, J.C.; Adamson, A.J. Accuracy of estimates of food portion size using food photographs-The importance of using age-appropriate tools. Public Health Nutr. 2006, 9, 509-514. [CrossRef] [PubMed]

74. Schlundt, D.G.; Buchowski, M.S.; Hargreaves, M.K.; Hankin, J.H.; Signorello, L.B.; Blot, W.J. Separate estimates of portion size were not essential for energy and nutrient estimation: Results from the Southern Community Cohort food-frequency questionnaire pilot study. Public Health Nutr. 2007, 10, 245-251. [CrossRef] [PubMed]

75. Magarey, A.; Watson, J.; Golley, R.K.; Burrows, T.; Sutherland, R.; McNaughton, S.A.; Denney-Wilson, E.; Campbell, K.; Collins, C. Assessing dietary intake in children and adolescents: Considerations and recommendations for obesity research. Int. J. Pediatr. Obes. 2011, 6, $2-11$. [CrossRef] [PubMed]

76. Magarey, A.; Golley, R.; Spurrier, N.; Goodwin, E.; Ong, F. Reliability and validity of the Children's Dietary Questionnaire; a new tool to measure children's dietary patterns. Int. J. Pediatr. Obes. 2009, 4, 257-265. [CrossRef] [PubMed]

77. Bentley, B. A review of methods to measure dietary sodium intake. J. Cardiovasc. Nurs. 2006, 21, 63-67. [CrossRef] [PubMed]

78. Supreme Council of Health (Qatar). Qatar Dietary Guidelines; Supreme Council of Health: Doha, Qatar, 2015. Available online: http://eservices.sch.gov.qa/qdg/En/download.jsp (accessed on 2 August 2015).

(C) 2015 by the authors; licensee MDPI, Basel, Switzerland. This article is an open access article distributed under the terms and conditions of the Creative Commons Attribution license (http://creativecommons.org/licenses/by/4.0/). 